\title{
Agrilus (Anambus) peloritanus n. sp. from eastern Sicily, Italy (Coleoptera Buprestidae)
}

\author{
Gianfranco Curletti \\ c/o Museo civico di Storia Naturale, Carmagnola, Italy; e-mail: giancurletti@gmail.com - ORCID: 0000-0002-8881- \\ 6463
}

\begin{abstract}
A new species of Agrilus Curtis, 1835 (Coleoptera Buprestidae) found in the Peloritani Mountains, a mountain range in north-western Sicily (Italy), is described. This new species is similar to A. litura Kiesenwetter, 1857 but his aedeagus has membranous appendages on the outer side of the parameres, a character which characterizes many tropical species, and, apparently, unique among the fauna of western Europe.
\end{abstract}

KEY WORDS Agrilus; nova species; Italy; Peloritani Mountains; Malabotta Wood; Quercus.

Received 28.07.2021; accepted 18.10.2021; published online 20.12.2021

\section{INTRODUCTION}

While conducting research aimed at elucidating the Buprestidae fauna of Polverello Mount of the Peloritani Mountains in Messina Province, Italy (Curletti, 2021), we had the opportunity to visit the Malabotta Wood, one of the oldest remnant forests in Sicily, and populated by secular oaks, beeches, maples located only a few km away. The short excursion led to the discovery of an undescribed species of Agrilus on the foliage of a centuries-old, naturally fallen oak. This new species is described here.

\section{MATERIAL AND METHODS}

The research was carried out exclusively on sight, to minimize any negative impact to the forest environment. The specimen was prepared dried and glued on cardboard for study, description and preservation. Photographs were taken with a Coolpix P6000 camera connected to a stereomicro- scope Leica MZ6, then processed and focus stacked using Adobe Photoshop CS5 Extended version 12.0. The species description follows the procedure detailed in Curletti (2010), an approach that emphasizes the use of distinctive characters combined with photographs to eliminate the need for repetitive morphological descriptions that contain many unimportant, repetitive, and subjective characters.

\section{RESULTS}

\section{Systematics}

Agrilus peloritanus n. sp.

https://zoobank.org:act:6269A0DB-DBC6-45459482-E18A53FDAD3E

MATERIAL EXAMined. Holotype male: Italy, Sicily, Messina, Malabotta Forest, $37^{\circ} 57^{\prime} 17^{\prime \prime} \mathrm{N}$, 15³'10"E, 25.VI.2021, Curletti G., Gigli M. and Bruschi S. legit. (Curletti coll., Carmagnola, Italy). 


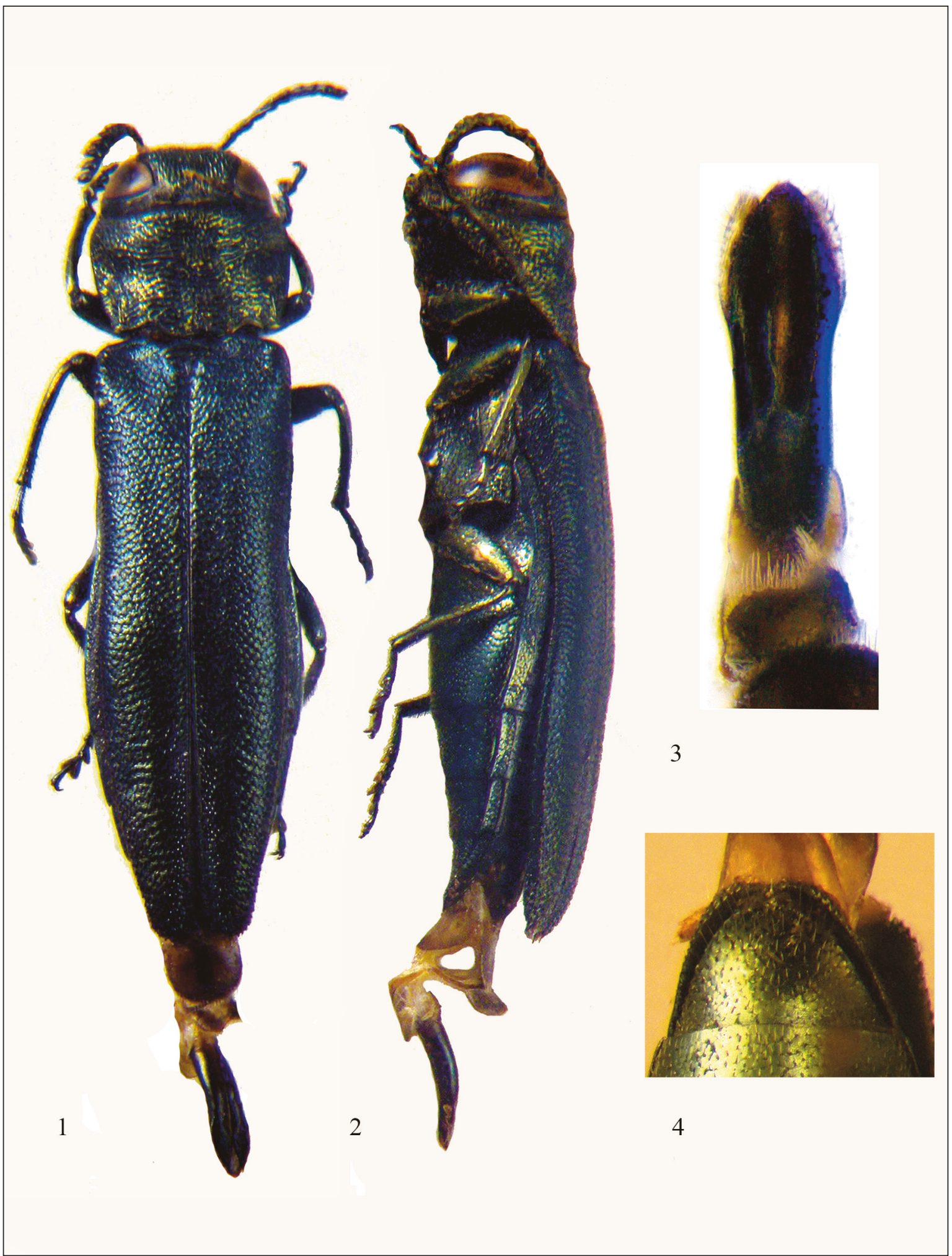

Figure 1. Agrilus peloritanus n. sp., holotype from Malabotta Forest (Messina, NE-Sicily, Italy). Figure 2. Agrilus peloritanus n. sp., holotype profile. Figure 3. Agrilus peloritanus n. sp., holotype aedeagus, $1.2 \mathrm{~mm}$. Figure 4. Agrilus peloritanus $\mathrm{n}$. sp., holotype last visible ventrite. 
DesCriPtion of holotyPe. Male (Figs. 1, 2). Length $5.8 \mathrm{~mm}$. Body shiny metallic, dorsal surface slightly two-tone with green-yellow head and pronotum and olive-green elytra. Head globose in dorsal view, with eyes not protruding from head outline. Vertex narrow, only $1 / 4$ width of anterior margin of pronotum. Frons green, glabrous except for a few short, scattered white hairs just above the epistome, which is carinated. Antennae serrate from antennomere 4.

Pronotum glabrous, wider anteriorly, with slightly arched lateral margins and obtuse posterior angles. Prehumeral carinae short, only $1 / 5$ length of lateral margin. Marginal and submarginal carinae joined at base. Disc with two vague median depressions behind vertex and in front of scutellum respectively. Sculpture robust, thick and arranged transversely. Anterior margin of prosternal lobe broadly, moderately sinuous. Prosternal process longitudinally concave, with longer pubescence, narrowed apically, with angles absent (see Jendek $\&$ Grebrennikov, 2011). Scutellum transversely carinate.

Elytra with longitudinal vitta of white pubescence along suture in distal quarter; apices separately arcuate, micro-denticulate. Ventral surface metallic green-gray, with short, barely visible, regularly arranged pubescence. Last visible ventrite with rounded apex. Legs with bronzed reflections. Metatarsa almost as long as metatibia; tarsomere 1 as long as 2-4 combined. Anterior claws bifid, posterior toothed, with inner spur longer than outer.

Aedeagus strongly sclerotized, slightly curved, sinuous on sides in basal half; parameres with subtransparent diaphanous appendix on sides. Apex of the median lobe sub-rounded (Fig. 3).

Etymology. Named for the Peloritani Mountains (Sicily, Italy) where the type locality is located.

DistribUtion AND BIOLOGY. Agrilus peloritanus n. sp. is currently known only from the type locality: Malabotta Forest (Messina, NE-Sicily, Italy).

The holotype was found among the withered foliage of a centuries-old naturally fallen oak (Quercus sp.) along with several other species of Agrilus: A. hastulifer (Ratzeburg, 1837), A. laticornis (Illiger, 1803), A. angustulus (Illiger, 1803), A. obscuricollis Kiesenwetter 1857.
REMARKS. Agrilus peloritanus n. sp. has unique characters compared to other congeners in the European fauna that place it in an intermediate position between the subgenera Agrilus (Anambus) Thomson, 1864 and Agrilus (s. str.). The entire apical margin of the last visible ventrite would place it in Agrilus (s. str.); however, the general aspect and strongly sclerotized aedeagus align it more closely with Agrilus (Anambus).

The aedeagus has membranous appendages on the outer side of the parameres, a character defined as "winged" by Curletti (2019), which characterizes many tropical species, but is apparently unique among the fauna of western Europe.

Agrilus peloritanus n. sp. superficially resembles $A$. litura Kiesenwetter, 1857 which has been reported from throughout western Europe, including northern Italy (Curletti, 2000), due to the apical pubescent vittae on the elytra. In addition, to the two characters mentioned above, A. peloritanus $\mathrm{n}$. sp. is distinguished by its more slender and elongated shape, the coloring of the pronotum, the more rounded head, the shorter and straighter prehumeral carinae, the different arrangement of the apical pubescence and the rounded margin of the apical ventrite (Fig. 4). This last character, which is peculiar and anomalous in the subgenus Agrilus (Anambus), suggests that the species could be a pre-glacial relict that has remained isolated on this mountain range.

\section{ACKNOWLEDGMENTS}

I am very grateful to Ted MacRae (Wildwood, Missouri) for his help in the English language.

\section{REFERENCES}

Curletti G., 2000. Aggiornamenti alla Checklist delle specie della fauna italiana. III Contributo, Fasc. 52, Coleoptera Elateroidea, Buprestoidea. Bollettino della Società entomologica italiana, 132: 273-277.

Curletti G., 2010. New species of the genus Agrilus Curtis, 1825, from Nicaragua and Panama (Coleoptera: Buprestidae: Agrilinae). Zootaxa, 2333: 59-68.

Curletti G., 2019. Nuove specie tropicali del genere Agrilus Curtis, 1825 (Coleoptera, Buprestidae). Bollettino del Museo regionale di Scienze naturali di Torino, 35: 33-58. 
Curletti G., 2021. Two new species of Agrilus Curtis, 1825 (Coleoptera Buprestidae) from Sicily, with one of Maghreb gravitation. Biodiversity Journal, 12:
463-466.

Jendek E. \& Grebennikov V., 2011. Agrilus (Coleoptera, Buprestidae) of East Asia. Jan Farkač, Prague: 362 pp. 